\title{
Characteristics of Multidrug Resistant Shigella and Vibrio cholerae 01 Infections in Patients Treated at an Urban and a Rural Hospital in Bangladesh
}

\author{
Sumon Kumar Das, ${ }^{1}$ Erik H. Klontz, ${ }^{1}$ Ishrat J. Azmi, ${ }^{1}$ Abu I. M. S. Ud-Din, ${ }^{1}$ \\ Mohammod Jobayer Chisti, ${ }^{1}$ Mokibul Hassan Afrad, ${ }^{1}$ Mohammad Abdul Malek, ${ }^{1}$ \\ Shahnawaz Ahmed, ${ }^{1}$ Jui Das, ${ }^{1}$ Kaisar Ali Talukder, ${ }^{1}$ Mohammed Abdus Salam, ${ }^{1}$ \\ Pradip Kumar Bardhan, ${ }^{1}$ Abu Syed Golam Faruque, ${ }^{1}$ and Karl C. Klontz ${ }^{2}$ \\ ${ }^{1}$ Centre for Nutrition and Food Security (CNFS), International Centre for Diarrheal Disease Research, \\ Bangladesh (icddr,b), 68 Shaheed Tajuddin Ahmed Sarani, Mohakhali, Dhaka 1212, Bangladesh \\ ${ }^{2}$ Office of Analytics and Outreach, Center for Food Safety and Applied Nutrition, Food and Drug Administration, \\ 5100 Paint Branch Parkway, College Park, MD 20740, USA \\ Correspondence should be addressed to Abu Syed Golam Faruque; gfaruque@icddrb.org
}

Received 6 October 2013; Accepted 10 November 2013

Academic Editors: R. R. Beumer and D. Rodriguez-Lazaro

Copyright (C) 2013 Sumon Kumar Das et al. This is an open access article distributed under the Creative Commons Attribution License, which permits unrestricted use, distribution, and reproduction in any medium, provided the original work is properly cited.

We determined the frequency of multidrug resistant (MDR) infections with Shigella spp. and Vibrio cholerae O1 at an urban (Dhaka) and rural (Matlab) hospital in Bangladesh. We also compared sociodemographic and clinical features of patients with MDR infections to those with antibiotic-susceptible infections at both sites. Analyses were conducted using surveillance data from the International Centre for Diarrhoeal Disease Research, Bangladesh (icddr,b), for the years 2000-2012. Compared to patients with antibiotic-susceptible for Shigella infections, those in Dhaka with MDR shigellosis were more likely to experience diarrhea for $>24$ hours, while, in Matlab, they were more likely to stay inhospital $>24$ hours. For MDR shigellosis, Dhaka patients were more likely than those in Matlab to have dehydration, stool frequency $>10$ /day, and diarrheal duration $>24$ hours. Patients with MDR Vibrio cholerae $\mathrm{O} 1$ infections in Dhaka were more likely than those in Matlab to experience dehydration and stool frequency $>10 /$ day. Thus, patients with MDR shigellosis and Vibrio cholerae O1 infection exhibited features suggesting more severe illness than those with antibiotic-susceptible infections. Moreover, Dhaka patients with MDR shigellosis and Vibrio cholerae O1 infections exhibited features indicating more severe illness than patients in Matlab.

\section{Introduction}

Shigella and Vibrio cholerae $\mathrm{O} 1$ are widely recognized causes of dysentery and acute watery diarrhea, respectively $[1,2]$. Both have been responsible for producing epidemics [3] and often require antibiotic treatment to mitigate the severity of disease [4-6]. For Shigella infections, in particular, increasing antibiotic resistance has led to fewer antibiotics capable of producing bacteriostatic or bactericidal minimum inhibitory concentrations (MICs) $[5,7]$. The challenge is compounded by the fact that while the regional prevalence of infection may be similar, rates of antibiotic resistance may differ substantially from one nation to another $[5,8]$.

Since 1979 and 2000, the International Centre for Diarrhoeal Disease Research, Bangladesh (icddr,b), has tested a systematic random sample of patients seeking care at an urban Dhaka Hospital and rural Matlab Treatment Centre for a spectrum of diarrhea-causing pathogens, including Shigella and Vibrio cholerae O1 [9]. Antimicrobial susceptibility patterns for these two pathogens are determined to inform clinicians about appropriate antibiotic treatment options [10]. Underscoring the need for antimicrobial sensitivity testing is 


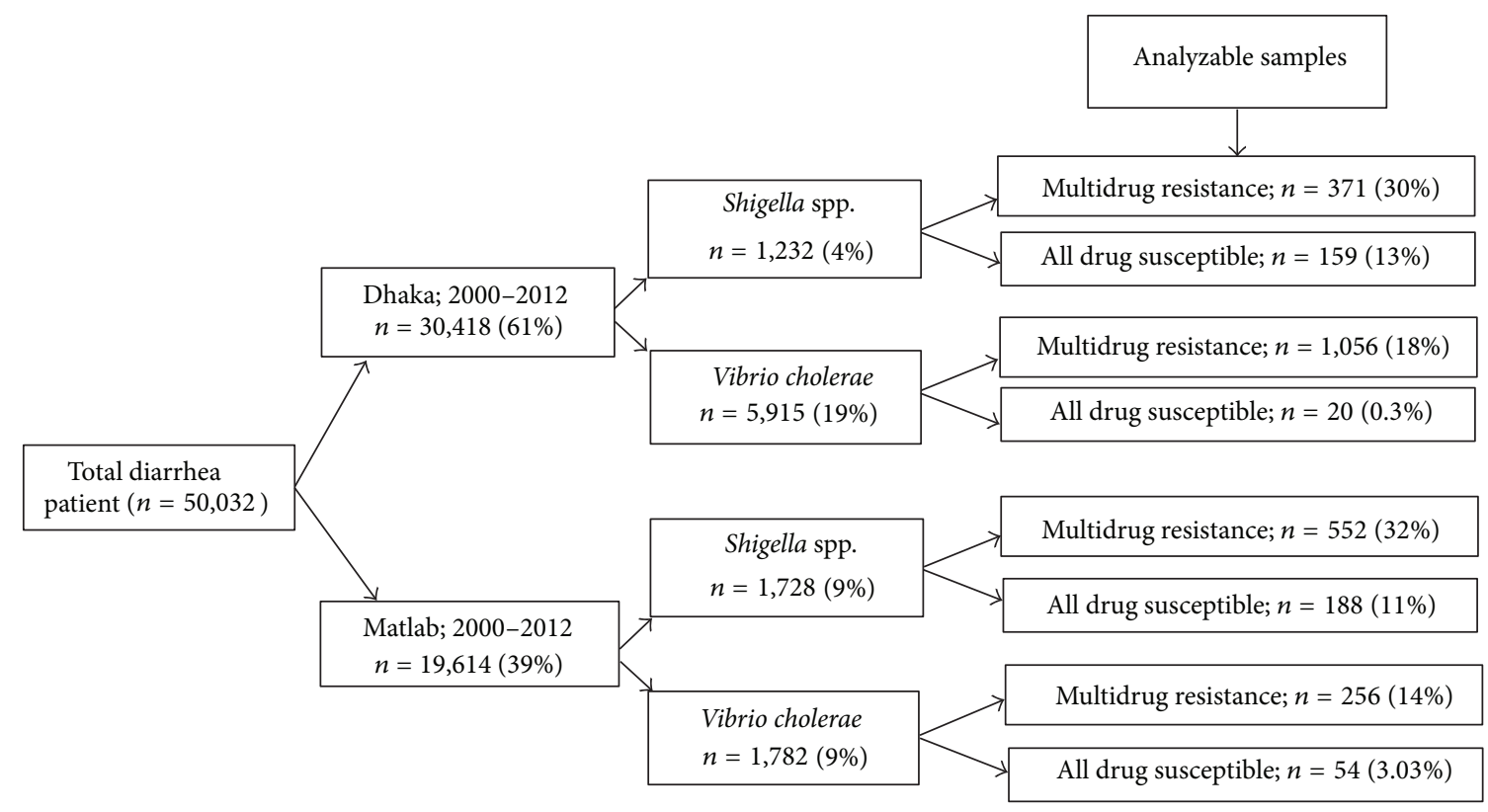

Figure 1: Sampling frame, testing of patients with diarrheal disease for multidrug resistant infections due to Shigella spp. or Vibrio cholerae O1, International Centre for Diarrhoeal Disease Research (icddr,b), Bangladesh, 2000-2012.

the emergence of multidrug resistance (MDR), defined here as isolates resistant to $\geq 3$ drugs [11-13]. Infections due to MDR strains are important not only because they are more difficult to treat but also because they may lead to higher fatality rates $[14,15]$. Resource constraints in developing nations such as Bangladesh have limited the amount of information about the clinical features of MDR Shigella and Vibrio cholerae $\mathrm{O} 1$ infections. To address this gap, we determined the proportion of patients exhibiting MDR Shigella or Vibrio cholerae O1 infections at icddr,b from 2000 to 2012. We also studied sociodemographic and clinical features of MDR infections compared to antibiotic-susceptible infections, and compared these features in patients with MDR infections treated at the urban (Dhaka) and rural (Matlab) hospitals.

\section{Materials and Methods}

\subsection{Study Sites}

2.1.1. Dhaka Hospital. Dhaka Hospital is located in the capital of Bangladesh. The hospital was established in 1962 by icddr,b, and currently provides free care and treatment to around 140,000 patients each year. The Diarrheal Disease Surveillance System (DDSS), approved by the Research Review Committee and Ethical Review Committee, has operated at icddr,b since 1979 to collect data on patient populations. From 1979 to 1995, microbiologic tests for a spectrum of diarrheal etiologies were conducted on a systematic sample of $4 \%$ of patients who attended icddr,b, whereas, since 1996, $2 \%$ of patients have been sampled to account for a neardoubling in the number of patients seeking care at icddr,b. A structured questionnaire is used to collect information on clinical, epidemiological, and demographic characteristics of patients, the feeding practices of infants and young children, and the use of drug and fluid therapy at home.

2.1.2. Matlab Hospital. Since 1963, icddr,b has maintained a facility in rural Matlab, located about $55 \mathrm{~km}$ from Dhaka, for treating patients with diarrhea in the region. Each year, the facility provides free treatment to 20,000 patients with diarrhea. At Matlab, unlike at the Dhaka facility, every patient with diarrhea is screened for the spectrum of diarrheal pathogens assessed as part of the DDSS.

2.2. Study Sample. Clinical and epidemiologic details were abstracted from the electronic data archive of DDSS for patients with diarrhea treated at icddr,b facilities in Dhaka and Matlab from 2000 to 2012. We compared sociodemographic and clinical features of patients from whom MDR Shigella spp. or Vibrio cholerae $\mathrm{O} 1$ was recovered with patients whose diarrheal stools yielded susceptible strains of the respective pathogens. Figure 1 illustrates the sampling frame for the study.

2.3. Laboratory Methodology. Fresh whole stool specimens collected from patients were examined at either the central icddr,b laboratory in Dhaka or at the Matlab clinical laboratory. Using standard laboratory methods described elsewhere $[16,17]$, each specimen was screened for common enteric pathogens, including Shigella spp. and Vibrio cholerae O1.

Bacterial susceptibility to antimicrobial agents was determined by the disk diffusion method as recommended by the Clinical Laboratory Standards Institute (CLSI 2010, June update) with commercial antimicrobial discs (Oxoid, Basingstoke, UK) [18]. The antibiotic discs used in this study for Shigella spp. included ampicillin $(10 \mu \mathrm{g})$, 
TABLE 1: Multidrug resistant (MDR) Shigella species recovered from patients in Dhaka and Matlab, International Centre for Diarrhoeal Disease Research (icddr,b), Bangladesh, 2000-2012.

\begin{tabular}{lccc}
\hline Shigella spp. & Dhaka; $n=371(\%)$ & Matlab, $n=552(\%)$ & OR $(95 \% \mathrm{CI}) P$ value \\
\hline Shigella flexneri & $257(69)$ & $495(90)$ & $0.26(0.18,0.37)<0.001$ \\
Shigella boydii & $68(18)$ & $33(6)$ & $0.28(0.18,0.45)<0.001$ \\
Shigella sonnei & $22(6)$ & $17(3)$ & $1.98(0.99,3.97) 0.051$ \\
Shigella dysenteriae 1 & $4(1)$ & $1(0.2)$ & $6.01(0.63,141.61) 0.016$ \\
Shigella dysenteriae & $20(5)$ & $6(1)$ & $5.19(1.95,14.56)<0.001$ \\
\hline
\end{tabular}

mecillinam $(25 \mu \mathrm{g})$, nalidixic acid $(30 \mu \mathrm{g})$, trimethoprimsulfamethoxazole, $(25 \mu \mathrm{g})$, and ciprofloxacin $(5 \mu \mathrm{g})$; and for $V$. cholerae O1: tetracycline $(30 \mu \mathrm{g})$, trimethoprim-sulfamethoxazole $(25 \mu \mathrm{g})$, erythromycin $(15 \mu \mathrm{g})$, ciprofloxacin $(5 \mu \mathrm{g})$, and azithromycin $(15 \mu \mathrm{g})$ (Dhaka only) [18].

2.4. Data Analysis. Data were analyzed using Statistical Package for Social Sciences (SPSS) Windows (Version 15.2; Chicago, IL) and Epi Info (Version 6.0, USD, Stone Mountain, GA). We compared differences in proportions using the Chi-square test. A probability value ( $P$ value) of $<0.05$ was considered to confer statistical significance. Magnitudes of association were determined by estimating odds ratios (OR) and $95 \%$ confidence intervals (CI). To identify MDR strains, we determined the frequency with which isolates exhibited resistance to $\geq 3$ antibiotics. We first compared sociodemographic features of patients with MDR infections versus those with susceptible infections. Next, focusing solely on MDR infections, we determined whether patients treated in Dhaka differed from those in Matlab in terms of sociodemographic or clinical features. All statistically significant differences ascertained by univariate analysis were entered into a logistic regression model to calculate adjusted odds ratios, $P$ values, and $95 \%$ confidence intervals.

\section{Results}

3.1. Shigella spp. From 2000 to 2012, the number of patients who yielded MDR Shigella spp. in Dhaka and Matlab was $371 / 1,232(30 \%)$ and 552/1,728 (32\%), respectively (Figure 1). S. flexneri was recovered from a greater proportion of patients in Matlab compared to Dhaka, whereas S. boydii was recovered from a greater proportion of patients in Dhaka versus Matlab (Table 1). Resistance to ampicillin + nalidixic acid + trimethoprim-sulfamethoxazole was the most common resistance pattern for patients treated at both Dhaka and Matlab (Table 2). In Dhaka, the percentages of isolates resistant to individual antibiotics were trimethoprimsulfamethoxazole (94\%), ampicillin (85\%), nalidixic acid (91\%), mecillinam (25\%), and ciprofloxacin (31\%). In Matlab, the percentages of isolates resistant to individual antibiotics were nalidixic acid (96\%), trimethoprim-sulfamethoxazole $(92 \%)$, ampicillin (87\%), ciprofloxacin (32\%), and mecillinam (12\%).

In Dhaka, compared to patients with antibioticsusceptible Shigella infections, those with MDR infections were more likely be male and to experience diarrhea for
$>24$ hours (Table 3). In Matlab, patients with MDR Shigella infections were more likely than those with susceptible infections to stay in hospital $>24$ hours and to report having used antimicrobials at home prior to coming to hospital (Table 4). For MDR Shigella infections, patients in Dhaka were more likely than those in Matlab to be male and to have dehydration, frequency of stools $>10 /$ day, and duration of diarrhea $>24$ hours (Table 5).

3.2. Vibrio cholerae O1. From 2000 to 2012, the number of patients who yielded MDR Vibrio cholerae O1 in Dhaka and Matlab was 1,056/5,915 (18\%) and 256/1,782 (15\%), respectively (Figure 1). In Dhaka, resistance to trimethoprimsulfamethoxazole + tetracycline + erythromycin + furazolidone was the most common resistance pattern, while in Matlab it was trimethoprim-sulfamethoxazole + tetracycline + erythromycin (Table 2). In Dhaka, the proportions of isolates resistant to individual antibiotics were trimethoprim-sulfamethoxazole (99\%), furazolidone (99\%), erythromycin (85\%), tetracycline (98\%), ciprofloxacin (5\%), and azithromycin (5\%). In Matlab, the percentages of isolates resistant to individual antibiotics were trimethoprimsulfamethoxazole (99\%), furazolidone (42\%), erythromycin $(65 \%)$, tetracycline $(93 \%)$, and ciprofloxacin $(<1 \%)$.

Patients with MDR Vibrio cholerae O1 infections in Dhaka were more likely than those in Matlab to experience a frequency of stools of $>10 /$ day, dehydration, and the presence in stools of 1-10 macrophages per high power field (Table 6).

\section{Discussion}

To our knowledge, few studies have assessed differences in sociodemographic and clinical features of multidrug resistant versus susceptible infections due to Shigella spp. within a single nation or to compare these features for multidrug resistant infections due to Shigella spp. and Vibrio cholerae $\mathrm{O} 1$ at an urban versus a rural treatment center [19]. Although multidrug resistant infections are a problem globally, the ease of availability of antibiotics to the public at large in nations such as Bangladesh may expedite the rate at which resistance develops [20]. In the present study, the proportion of multidrug resistant Shigella and Vibrio cholerae O1 isolates recovered from patients in urban Dhaka was similar to that in rural Matlab. Of concern, in both hospital settings, there was evidence of resistance to mecillinam and ciprofloxacin, drugs commonly used for the treatment of shigellosis and, in the case of ciprofloxacin, cholera. In general, the emergence 
TABLE 2: Multidrug resistant Shigella spp. and Vibrio cholerae O1 recovered from patients with diarrhea, Dhaka and Matlab, International Centre for Diarrhoeal Research Bangladesh (icddr,b), 2000-2012.

\begin{tabular}{|c|c|c|c|c|c|c|}
\hline \multirow{2}{*}{ Antimicrobials } & \multicolumn{3}{|c|}{ Shigella spp. } & \multicolumn{3}{|c|}{ Vibrio cholerae } \\
\hline & Dhaka; $n=371(\%)$ & Matlab; $n=552(\%)$ & OR (95\% CI) $P$ & $\begin{array}{c}\text { Dhaka; } \\
n=1056(\%)\end{array}$ & $\begin{array}{c}\text { Matlab; } \\
n=256(\%)\end{array}$ & OR (95\% CI) $P$ \\
\hline $\mathrm{AMP}+\mathrm{NAL}+\mathrm{TMST}$ & $203(55)$ & $301(56)$ & $\begin{array}{l}0.94(0.72,1.24) \\
0.715\end{array}$ & - & - & - \\
\hline $\mathrm{AMP}+\mathrm{NAL}+\mathrm{MEC}$ & $4(1)$ & $19(3)$ & $\begin{array}{l}0.31(0.09,0.96) \\
0.040\end{array}$ & - & - & - \\
\hline $\mathrm{AMP}+\mathrm{NAL}+\mathrm{CIP}$ & $1(0.3)$ & $20(4)$ & $\begin{aligned} 0.07 & (0.00,0.51) \\
& <0.001\end{aligned}$ & - & - & - \\
\hline $\mathrm{AMP}+\mathrm{TMST}+\mathrm{MEC}$ & - & $21(4)$ & - & - & - & - \\
\hline $\mathrm{AMP}+\mathrm{TMST}+\mathrm{CIP}$ & $18(5)$ & $1(0.2)$ & $\begin{aligned} 28.10 & (3.96,567.52) \\
& <0.001\end{aligned}$ & - & - & - \\
\hline $\mathrm{AMP}+\mathrm{CIP}+\mathrm{MEC}$ & $24(7)$ & - & - & - & - & - \\
\hline $\mathrm{AMP}+\mathrm{TMST}+\mathrm{AZI}$ & $5(1)$ & - & - & - & - & - \\
\hline $\mathrm{AMP}+\mathrm{CIP}+\mathrm{AZI}$ & $2(0.5)$ & - & - & - & - & - \\
\hline $\mathrm{AMP}+\mathrm{MEC}+\mathrm{AZI}$ & $2(0.5)$ & - & - & - & - & - \\
\hline TMST + CIP + AZI & $3(1)$ & - & - & - & - & - \\
\hline TMST + MEC + AZI & $2(0.3)$ & - & - & - & - & - \\
\hline $\mathrm{CIP}+\mathrm{MEC}+\mathrm{AZI}$ & $1(0.3)$ & - & - & - & - & - \\
\hline $\mathrm{NAL}+\mathrm{CIP}+\mathrm{MEC}$ & - & $20(4)$ & - & - & - & - \\
\hline NAL + TMST + MEC & $4(1)$ & $1(0.2)$ & $\begin{array}{c}6.01(0.63,141.61) \\
0.163\end{array}$ & - & - & - \\
\hline $\mathrm{NAL}+\mathrm{TMST}+\mathrm{CIP}$ & $22(6)$ & $67(12)$ & $\begin{array}{c}0.48(0.28,0.82) \\
0.005\end{array}$ & - & - & - \\
\hline TMST + CIP + MEC & $3(1)$ & $3(1)$ & $\begin{array}{c}1.49(0.24,9.27) \\
0.689\end{array}$ & - & - & - \\
\hline $\mathrm{TET}+\mathrm{TMST}+\mathrm{FUR}$ & - & - & - & $103(10)$ & $89(35)$ & $\begin{aligned} 0.20 & (0.14,0.29) \\
& <0.001\end{aligned}$ \\
\hline TET + FUR + ERY & - & - & - & - & $1(0.4)$ & - \\
\hline TMST + FUR + ERY & - & - & - & $7(1)$ & $17(7)$ & $\begin{aligned} 0.09 & (0.03,0.24) \\
& <0.001\end{aligned}$ \\
\hline TMST + FUR + CIP & - & - & - & - & - & - \\
\hline TET + TMST + ERY & - & - & - & $38(4)$ & $148(58)$ & $\begin{aligned} 0.03 & (0.02,0.04) \\
& <0.001\end{aligned}$ \\
\hline $\mathrm{AMP}+\mathrm{TMST}+\mathrm{CIP}+\mathrm{AZI}$ & $7(2)$ & - & - & - & - & - \\
\hline $\begin{array}{l}\mathrm{AMP}+\mathrm{TMST}+\mathrm{MEC}+ \\
\mathrm{AZI}\end{array}$ & $2(1)$ & - & - & - & - & - \\
\hline $\mathrm{AMP}+\mathrm{CIP}+\mathrm{MEC}+\mathrm{AZI}$ & $1(0.3)$ & - & - & - & - & - \\
\hline $\mathrm{AMP}+\mathrm{CIP}+\mathrm{NAL}+\mathrm{AZI}$ & $1(0.3)$ & - & - & - & - & - \\
\hline $\begin{array}{l}\mathrm{AMP}+\mathrm{NAL}+\mathrm{TMST}+ \\
\mathrm{CIP}\end{array}$ & $19(5)$ & $67(12)$ & $\begin{aligned} 0.39 & (0.22,0.68) \\
& <0.001\end{aligned}$ & - & - & - \\
\hline $\begin{array}{l}\mathrm{AMP}+\mathrm{NAL}+\mathrm{TMST}+ \\
\mathrm{MEC}\end{array}$ & $3(1)$ & - & - & - & - & - \\
\hline $\mathrm{AMP}+\mathrm{NAL}+\mathrm{CIP}+\mathrm{MEC}$ & $3(1)$ & $4(1)$ & $\begin{array}{c}1.12(0.20,5.92) \\
1.000\end{array}$ & - & - & - \\
\hline $\begin{array}{l}\mathrm{AMP}+\mathrm{CIP}+\mathrm{TMST}+ \\
\mathrm{MEC}\end{array}$ & $9(3)$ & - & - & - & - & - \\
\hline $\begin{array}{l}\text { TMST + NAL + CIP + } \\
\text { MEC }\end{array}$ & $1(0.3)$ & $3(1)$ & $\begin{array}{c}0.49(0.02,5.32) \\
0.652\end{array}$ & - & - & - \\
\hline $\mathrm{TMST}+\mathrm{TET}+\mathrm{ERY}+\mathrm{FUR}$ & - & - & - & $906(86)$ & - & - \\
\hline TMST + ERY + CIP + FUR & - & - & - & $1(0.1)$ & - & - \\
\hline $\mathrm{TMST}+\mathrm{TET}+\mathrm{ERY}+\mathrm{AZI}$ & - & - & - & $1(0.1)$ & - & - \\
\hline
\end{tabular}


TABLE 2: Continued.

\begin{tabular}{|c|c|c|c|c|c|c|}
\hline \multirow{2}{*}{ Antimicrobials } & \multicolumn{3}{|c|}{ Shigella spp. } & \multicolumn{3}{|c|}{ Vibrio cholerae } \\
\hline & Dhaka; $n=371(\%)$ & Matlab; $n=552(\%)$ & OR (95\% CI) $P$ & $\begin{array}{c}\text { Dhaka; } \\
n=1056(\%)\end{array}$ & $\begin{array}{c}\text { Matlab; } \\
n=256(\%)\end{array}$ & OR (95\% CI) $P$ \\
\hline $\begin{array}{l}\mathrm{AMP}+\mathrm{TMST}+\mathrm{NAL}+ \\
\mathrm{CIP}+\mathrm{MEC}\end{array}$ & $24(7)$ & $16(3)$ & $\begin{array}{c}2.32(1.16,4.64) \\
0.014\end{array}$ & - & - & - \\
\hline $\begin{array}{l}\mathrm{AMP}+\mathrm{TMST}+\mathrm{CIP}+ \\
\mathrm{MEC}+\mathrm{AZI}\end{array}$ & $7(1)$ & - & - & - & - & - \\
\hline $\begin{array}{l}\mathrm{FUR}+\mathrm{ERY}+\mathrm{CIP}+\mathrm{TMST} \\
+\mathrm{TET}\end{array}$ & - & - & - & - & $1(0.4)$ & - \\
\hline
\end{tabular}

AMP: Ampicillin; AZI: azithromycin; CIP: ciprofloxacin; ERY: erythromycin; FUR: furazolidin; MEC: mecillinam; NAL: nalidixic acid; TET: tetracycline; TMST: trimethoprim-sulfamethoxazole.

TABLE 3: Sociodemographic and clinical factors among patients with shigellosis, by drug resistance status, Dhaka, International Centre for Diarrhoeal Disease Research, Bangladesh (icddr,b), 2000-2012.

\begin{tabular}{|c|c|c|c|c|}
\hline Indicators & Multidrug resistant $n=371(\%)$ & Susceptible $n=159(\%)$ & OR $(95 \%$ CI $)$ & $\mathrm{aOR}(95 \% \mathrm{CI})$ \\
\hline Male sex & $225(61)$ & $111(70)$ & $6.72(3.25,14.23)^{*}$ & $1.58(1.02,2.43)^{*}$ \\
\hline Monthly family income $\geq 100$ USD & $345(93)$ & $147(93)$ & $1.08(0.50,2.31)$ & - \\
\hline Slum residence & $33(9)$ & $19(12)$ & $0.72(0.38,1.37)$ & - \\
\hline Nonsanitary latrine & $133(36)$ & $61(38)$ & $0.90(0.60,1.34)$ & - \\
\hline Not treated water & $249(67)$ & $103(65)$ & $1.11(0.74,1.67)$ & - \\
\hline Vomiting & $243(66)$ & $120(76)$ & $0.62(0.40,0.96)^{*}$ & $0.84(0.52,1.35)$ \\
\hline Abdominal pain & $206(56)$ & $76(48)$ & $1.36(0.92,2.01)$ & - \\
\hline Fever $\left(\geq 38^{\circ} \mathrm{C}\right)$ & 40 (11) & $7(4)$ & $2.62(1.10,6.57)^{*}$ & $2.18(0.93,5.12)$ \\
\hline Bloody or mucoid stool & $165(45)$ & $63(40)$ & $1.22(0.82,1.81)$ & - \\
\hline Frequency of stool (>10/day) & $189(51)$ & $75(47)$ & $1.16(0.79,1.72)$ & - \\
\hline Duration of diarrhea ( $>24$ hours) & $262(71)$ & $87(55)$ & $1.99(1.33,2.97)^{*}$ & $1.73(1.11,2.69)^{*}$ \\
\hline Duration of stay in hospital $>24 \mathrm{hrs}$ & $134(37)$ & $54(35)$ & $1.09(0.72,1.64)$ & - \\
\hline Some or severe dehydration & $211(57)$ & $84(53)$ & $1.18(0.80,1.74)$ & - \\
\hline Use of intravenous saline for rehydration & $77(21)$ & $27(17)$ & $1.28(0.77,2.14)$ & - \\
\hline Use of antimicrobials at home & $251(68)$ & $91(57)$ & $1.56(1.05,2.33)^{*}$ & $1.20(0.78,1.86)$ \\
\hline Red blood cell $(1$ to $>50)$ & $241(69)$ & $76(52)$ & $2.07(1.37,3.13)^{*}$ & $0.77(0.33,1.83)$ \\
\hline Faecal leukocyte $(11$ to $>50)$ & $272(78)$ & $88(60)$ & $2.34(1.51,3.62)^{*}$ & $1.62(0.81,3.24)$ \\
\hline Macrophage (1 to 10$)$ & $219(63)$ & $62(42)$ & $2.29(1.52,3.46)^{*}$ & $0.92,4.08)$ \\
\hline
\end{tabular}

${ }^{*} P<0.05$.

aOR: adjusted odds ratio.

of resistance poses a number of challenges by leading, in some instances, to an increase in morbidity and mortality and longer hospital stays, as a result of inadequate initial therapy or increased virulence [15]. Moreover, antibiotic resistance reduces choices for therapy and can cause health care costs to rise due to the need to use antimicrobial agents that are more expensive than those in current use.

While antibiotic resistance in both Shigella spp. and Vibrio cholerae $\mathrm{O} 1$ has serious ramifications, for Shigella spp. the phenomenon carries added weight given that susceptibility rarely returns after resistant strains have become endemic in a region $[12,21]$. Although $S$. dysenteriae 1 frequently develops resistance to new antibiotics initially, resistance is often acquired subsequently in the other Shigella species. In contrast, Vibrio cholerae $\mathrm{O} 1$ strains often revert to antibiotic susceptibility [12]. This phenomenon was observed during the study period when, abruptly in late 2004, Vibrio cholerae
O1 isolates at both Matlab and Dhaka demonstrated tetracycline resistance; however, two years later, in 2006, tetracycline susceptibility reappeared in large part [22].

We observed evidence that multidrug resistant infections due to Shigella spp. were associated with more severe illness compared to non-MDR strains. For example, patients in Dhaka from whom multiresistant Shigella spp. were recovered significantly were more likely to experience diarrhea for $>24$ hours compared to patients from whom susceptible isolates were recovered. Similarly, in Matlab, patients from whom multidrug resistant Shigella spp. was recovered are more likely than those with susceptible infections to stay in hospital $>24$ hours and to report having used antimicrobials at home prior to coming to hospital. We also found evidence of differing degrees of severity of multidrug resistant infections due to Shigella spp. and Vibrio cholerae $\mathrm{O} 1$ infections depending on whether patients resided in urban or rural areas 
TABLE 4: Sociodemographic and clinical factors among patients with shigellosis, by drug resistance status, Matlab, International Centre for Diarrhoeal Disease Research, Bangladesh (icddr,b), 2000-2012.

\begin{tabular}{|c|c|c|c|c|}
\hline Indicators & Multidrug resistant $n=552(\%)$ & Susceptible $n=188(\%)$ & OR $(95 \% \mathrm{CI})$ & $\mathrm{aOR}(95 \% \mathrm{CI})$ \\
\hline Male sex & $297(54)$ & $95(51)$ & $1.14(0.81,1.61)$ & - \\
\hline Monthly family income $\geq 100$ USD & $257(47)$ & $79(42)$ & $1.20(0.85,1.70)$ & - \\
\hline Nonsanitary latrine & $486(88)$ & $165(88)$ & $1.03(0.60,1.75)$ & - \\
\hline Not treated water & $544(99)$ & $186(99)$ & $0.73(0.11,3.75)$ & - \\
\hline Vomiting & $273(50)$ & $99(53)$ & $0.88(0.62,1.24)$ & - \\
\hline Abdominal pain & $370(67)$ & $130(69)$ & $0.91(0.62,1.32)$ & - \\
\hline Fever $\left(\geq 38^{\circ} \mathrm{C}\right)$ & $132(24)$ & $51(27)$ & $0.84(0.57,1.25)$ & - \\
\hline Bloody or mucoid stool & $425(77)$ & $126(67)$ & $1.65(1.13,2.40)^{*}$ & $1.23(0.80,1.87)$ \\
\hline Frequency of stool (>10/day) & $230(42)$ & $77(41)$ & $1.03(0.73,1.46)$ & - \\
\hline Duration of diarrhea (>24 hours) & $373(68)$ & $107(57)$ & $1.58(1.11,2.25)^{*}$ & $1.35(0.92,1.99)$ \\
\hline Duration of stay in hospital $>24 \mathrm{hrs}$ & $216(40)$ & $57(31)$ & $1.51(1.04,2.18)^{*}$ & $1.79(1.23,2.62)^{*}$ \\
\hline Some or severe dehydration & $108(20)$ & $53(28)$ & $0.62(0.42,0.92)^{*}$ & $0.69(0.45,1.06)$ \\
\hline Use of intravenous saline for rehydration & $24(4)$ & $9(5)$ & $0.90(0.39,2.14)$ & - \\
\hline Use of antimicrobials at home & $33(60)$ & $88(47)$ & $1.73(1.22,2.45)^{*}$ & $1.48(1.03,2.12)^{*}$ \\
\hline Red blood cell $(1$ to $>50)$ & $509(93)$ & $154(82)$ & $2.80(1.65,4.73)^{*}$ & $2.12(0.85,5.43)$ \\
\hline Faecal leukocyte $(11$ to $>50)$ & $527(96)$ & $166(89)$ & $3.17(1.62,6.22)^{*}$ & $1.78(0.66,4.85)$ \\
\hline Macrophage (1 to 10$)$ & $451(82)$ & $136(73)$ & $1.74(1.16,2.62)^{*}$ & $0.92(0.51,1.65)$ \\
\hline
\end{tabular}

${ }^{*} P<0.05$.

aOR: adjusted odds ratio.

TABLE 5: Sociodemographic and clinical features of patients with multidrug resistant Shigella infections in Dhaka compared to those in Matlab, International Centre for Diarrhoeal Disease Research, Bangladesh (icddr,b), 2000-2012.

\begin{tabular}{lcc}
\hline Indicators & OR $(95 \%$ CI $)$ & aOR $(95 \%$ CI $)$ \\
\hline Male sex & $1.24(0.94,1.64)$ & $1.52(1.08,2.16)^{*}$ \\
Vomiting & $1.94(1.47,2.57)^{*}$ & $1.26(0.87,1.82)$ \\
Abdominal pain & $0.61(0.46,0.81)^{*}$ & $0.87(0.59,1.28)$ \\
Fever $\left(\geq 38^{\circ}\right.$ C) & $0.38(0.26,0.57)^{*}$ & $0.39(0.25,0.65)^{*}$ \\
Bloody or mucoid stool & $0.24(0.18,0.32)^{*}$ & $0.39(0.26,0.62)^{*}$ \\
Frequency of stool $(>10 /$ day) & $1.45(1.11,1.91)^{*}$ & $1.83(1.28,2.59)^{*}$ \\
Duration of diarrhea $(>24$ hours $)$ & $1.15(0.86,1.55)$ & $1.64(1.07,2.52)^{*}$ \\
Duration of stay in hospital $>24$ hrs & $0.90(0.68,1.19)$ & $0.84(0.58,1.20)$ \\
Some or severe dehydration & $5.42(4.00,7.36)^{*}$ & $5.61(3.75,8.39)^{*}$ \\
Use of intravenous saline for rehydration & $5.80(3.51,9.66)^{*}$ & $1.53(0.79,2.94)$ \\
Use of antimicrobials at home & $1.38(1.03,1.83)^{*}$ & $1.42(0.97,2.08)$ \\
Red blood cell $(1$ to $>50)$ & $0.17(0.11,0.26)^{*}$ & $0.21(0.08,0.52)^{*}$ \\
Faecal leukocyte $(11$ to $>50)$ & $0.14(0.08,0.24)^{*}$ & $0.42(0.17,1.07)$ \\
Macrophage $(1$ to 10$)$ & $0.36(0.26,0.50)^{*}$ & $1.81(0.98,3.35)$ \\
\hline
\end{tabular}

${ }^{*} P<0.05$.

aOR: adjusted odds ratio.

of the country. For example, for infections with MDR Shigella spp., patients in Dhaka were more likely than those in Matlab to experience dehydration, a frequency of stools $>10 /$ day, and duration of diarrhea $>24$ hours. Similarly, patients with MDR Vibrio cholerae O1 infections in Dhaka were more likely than those in Matlab to experience dehydration, frequency of stools of $>10$ /day, and the presence of macrophages in stools. Further studies are needed to corroborate whether patients with multidrug resistant infections due to Shigella spp. and Vibrio cholerae $\mathrm{O} 1$ who reside in urban areas are, in fact, at elevated risk of experiencing more severe illness than patients in rural areas, and, if the findings are borne out, what factors contribute to this phenomenon. In the meantime, we hypothesize that differences in sociodemographic, nutritional, and economic characteristics of urban versus rural populations may, in part, explain our observations, as may differences in sources of drinking water and water-sanitation practices.

The present study has several limitations. Hospital-based data of the type incorporated in the Diarrheal Disease Surveillance System may not adequately represent the ill population at large. For example, a segment of the population in Bangladesh, particularly in rural regions, is known to 
TABLE 6: Sociodemographic and clinical features of patients with multidrug resistant Vibrio cholerae O1 infections in Dhaka compared to those in Matlab, International Centre for Diarrhoeal Disease Research, Bangladesh (icddr,b), 2000-2012.

\begin{tabular}{|c|c|c|c|c|}
\hline Indicators & Dhaka; $n=1,056(\%)$ & Matlab; $n=256(\%)$ & OR (95\% CI) & $\mathrm{aOR}(95 \% \mathrm{CI})$ \\
\hline Male sex & $607(56)$ & $126(46)$ & $1.39(1.05,1.85)^{*}$ & $1.40(0.79,2.48)$ \\
\hline Vomiting & $976(92)$ & $216(84)$ & $2.26(1.47,3.46)^{*}$ & $1.86(0.71,4.84)$ \\
\hline Abdominal pain & $448(42)$ & $131(51)$ & $0.70(0.53,0.93)^{*}$ & $0.50(0.28,0.89)^{*}$ \\
\hline Fever $\left(\geq 38^{\circ} \mathrm{C}\right)$ & $7(1)$ & $16(6)$ & $0.10(0.04,0.26)^{*}$ & $0.09(0.02,0.57)^{*}$ \\
\hline Watery stool & $1048(99)$ & $245(96)$ & $5.88(2.17,16.19)^{*}$ & $0.27(0.00,18.62)$ \\
\hline Frequency of stool (>10/day) & $592(56)$ & $237(93)$ & $2.31(1.73,3.10)^{*}$ & $3.32(1.78,6.17)^{*}$ \\
\hline Duration of diarrhea (>24 hours) & $369(35)$ & $75(29)$ & $1.30(0.95,1.76)^{*}$ & $0.98(0.49,1.95)$ \\
\hline Duration of stay in hospital $>24 \mathrm{hrs}$ & $391(39)$ & $170(67)$ & $0.31(0.23,0.42)^{*}$ & $0.39(0.22,0.71)^{*}$ \\
\hline Some or severe dehydration & $998(94)$ & $214(84)$ & $3.44(2.20,5.37)^{*}$ & $3.07(1.13,8.32)^{*}$ \\
\hline Use of intravenous saline for rehydration & $828(79)$ & $152(59)$ & $2.58(1.91,3.48)^{*}$ & $1.90(0.88,4.11)$ \\
\hline Use of antimicrobials at home & $454(43)$ & $126(49)$ & $0.78(0.59,1.03)$ & $1.35(0.75,2.45)$ \\
\hline Red blood cell $(1$ to $>50)$ & $456(44)$ & $167(66)$ & $0.39(0.29,0.53)^{*}$ & $0.19(0.09,0.39)^{*}$ \\
\hline Faecal leukocyte $(11$ to $>50)$ & $508(49)$ & $198(79)$ & $0.26(0.18,0.36)^{*}$ & $0.35(0.17,0.73)^{*}$ \\
\hline Macrophage (1 to 10$)$ & $292(28)$ & $33(13)$ & $2.58(1.72,3.88)^{*}$ & $11.75(4.87,28.31)^{*}$ \\
\hline
\end{tabular}

${ }^{*} P<0.05$.

aOR: adjusted odds ratio.

use medicinal plants and traditional healers as a first-line of health care to cure gastrointestinal disorders [23]. Consequently, it is possible that sociodemographic and clinical features of patients with shigellosis and cholera described here may not be completely representative of all infections that occurred in the study area and study period. In addition, the results of antibiotic resistance testing we used were largely qualitative-presence, absence-as opposed to a quantitative nature as provided by minimum inhibitory concentrations. Thus, we were unable to ascertain pathogen-antibiotic relationships, wherein resistance levels may have approached limits known to confer resistance. Finally, our results did not incorporate the role of virulence factors or genetic typing that could have added valuable insight into outcomes of interest.

Notwithstanding these limitations, we believe that our results justify further research to determine, first, whether multidrug resistant strains of Shigella and Vibrio cholerae $\mathrm{O} 1$ are associated with more severe infections than antibioticsusceptible strains, and, if so, what factors increase the severity of infections, and second, whether multidrug resistant infections caused by these two pathogens produce more severe infections in urban versus rural regions. Answers to these questions may help in efforts to prevent infections due to Shigella spp. and Vibrio cholerae O1, both of which are often leading bacterial causes of diarrhea in developing nations.

\section{Conflict of Interests}

The authors declared no potential conflict of interests. All authors confirmed that there is no professional affiliation, financial agreement, or other involvement with any company whose product figures prominently in the submitted paper.

\section{Acknowledgments}

Hospital surveillance was funded by icddr,b and the Government of the People's Republic of Bangladesh through
IHP-HNPRP. icddr,b acknowledges with gratitude the commitment of the Government of the People's Republic of Bangladesh for their research efforts. icddr,b also gratefully acknowledges the following donors who provide unrestricted support to the Centre's research efforts: Australian Agency for International Development (AusAID), Government of the People's Republic of Bangladesh, Canadian International Development Agency (CIDA), Swedish International Development Cooperation Agency (Sida), Swiss Agency for Development and Cooperation (SDC), and Department for International Development, UK (DFID).

\section{References}

[1] S. K. Das, S. Ahmed, and F. Ferdous, "Changing emergence of Shigella sero-groups in Bangladesh: observation from four different diarrheal disease hospitals," PLoS One, vol. 8, no. 4, Article ID e62029, 2013.

[2] F. Chowdhury, A. I. Khan, A. S. G. Faruque, and E. T. Ryan, "Severe, acute watery diarrhea in an adult," PLoS Neglected Tropical Diseases, vol. 4, no. 11, article e898, 2010.

[3] K. L. Kotloff, J. P. Winickoff, B. Ivanoff et al., "Global burden of Shigella infections: implications for vaccine development and implementation of control strategies," Bulletin of the World Health Organization, vol. 77, no. 8, pp. 651-666, 1999.

[4] D. Sur, T. Ramamurthy, J. Deen, and S. K. Bhattacharya, "Shigellosis: challenges \& management issues," Indian Journal of Medical Research, vol. 120, no. 5, pp. 454-462, 2004.

[5] G. P. Pazhani, S. K. Niyogi, A. K. Singh et al., "Molecular characterization of multidrug-resistant Shigella species isolated from epidemic and endemic cases of shigellosis in India," Journal of Medical Microbiology, vol. 57, no. 7, pp. 856-863, 2008.

[6] M. H. Dick, M. Guillerm, F. Moussy, and C. L. Chaignat, "Review of two decades of cholera diagnostics-how far have we really come?” PLOS Neglected Tropical Diseases, vol. 6, no. 10, Article ID e1845, 2012. 
[7] F. C. Tenover, "Mechanisms of antimicrobial resistance in bacteria," American Journal of Medicine, vol. 119, supplement 1, pp. S3-S10, 2006.

[8] K.-L. Thong, C. H. Hoe, Y. T. Koh, and R. M. Yasin, "Prevalence of multidrug-resistant Shigella isolated in Malaysia," Journal of Health Population and Nutrition, vol. 20, no. 4, pp. 356-358, 2002.

[9] B. J. Stoll, R. I. Glass, M. I. Huq, M. U. Khan, J. E. Holt, and H. Banu, "Surveillance of patients attending a diarrhoeal disease hospital in Bangladesh," British Medical Journal, vol. 285, no. 6349, pp. 1185-1188, 1982.

[10] S. K. Das, S. Ahmed, F. D. Ferdous et al., "Etiologic studies of patients visiting different diarrhoealdisease facilities in Bangladesh," Journal of Infection in Developing Country. In press.

[11] S. Ashkenazi, M. May-Zahav, J. Sulkes, R. Zilberberg, and Z. Samra, "Increasing antimicrobial resistance of Shigella isolates in Israel during the period 1984 to 1992," Antimicrobial Agents and Chemotherapy, vol. 39, no. 4, pp. 819-823, 1995.

[12] D. A. Sack, C. Lyke, C. McLaughlin, and S. Voravit, "Antimicrobial resistance in shigellosis, cholera and campylobacteriosis," Tech. Rep., World Health Organization, Geneva, Switzerland, 2001.

[13] A. A. M. Lima, N. L. Lima, M. C. N. Pinho et al., "High frequency of strains multiply resistant to ampicillin, trimethoprim-sulfamethoxazole, streptomycin, chloramphenicol, and tetracycline isolated from patients with shigellosis in northeastern Brazil during the period 1988 to 1993," Antimicrobial Agents and Chemotherapy, vol. 39, no. 1, pp. 256-259, 1995.

[14] P. G. Sengupta, S. Mandal, D. Sen, P. Das, B. C. Deb, and S. C. $\mathrm{Pal}$, "Multidrug resistant epidemic shigellosis in a village in west Bengal, 1984," Indian Journal of Public Health, vol. 34, no. 1, pp. 15-19, 1990.

[15] I. H. Spicknall, B. Foxman, C. F. Marrs, and J. N. Eisenberg, "A modeling framework for the evolution and spread of antibiotic resistance: literature review and model categorization," American Journal of Epidemiology, vol. 178, pp. 508-520, 2013.

[16] "Programme for control of diarrheal disease," in Manual For Laboratory Investigation of Acute Enteric Infections, World Health Organization, Geneva, Switzerland, 1987.

[17] F. Qadri, A. I. Khan, A. S. G. Faruque et al., "Enterotoxigenic Escherichia coli and Vibrio cholerae diarrhea, Bangladesh, 2004," Emerging Infectious Diseases, vol. 11, no. 7, pp. 1104-1107, 2005.

[18] Clinical and Laboratory Standard Institute (CLSI), "Performance Standards for Antimicrobial Susceptibility Testing; 20th Informational Supplement (June 2010, Update)," CLSI document M100-S20-U, CLSI, Clinical and Laboratory Standard Institute, Fort Wayne, Ind, USA, 2010.

[19] M. E. Beatty, J. B. Ochieng, W. Chege et al., "Sporadic paediatric diarrhoeal illness in urban and rural sites in Nyanza Province, Kenya," East African Medical Journal, vol. 86, no. 8, pp. 387-398, 2009.

[20] P. Karmakar and M. M. Sattar, "Antibiotic prescribing pattern in Bangladesh," Banglaesh Journal of Progressive Science \& Technology, vol. 10, no. 1, pp. 13-16, 2012.

[21] L. von Seidlein, R. K. Deok, M. Ali et al., "A multicentre study of Shigella diarrhoea in six Asian countries: disease burden, clinical manifestations, and microbiology," PLoS Medicine, vol. 3, no. 9, article e353, 2006.

[22] A. S. G. Faruque, K. Alam, M. A. Malek et al., "Emergence of multidrug-resistant strain of Vibrio cholerae OI in Bangladesh and reversal of their susceptibility to tetracycline after two years," Journal of Health, Population and Nutrition, vol. 25, no. 2, pp. 241-243, 2007.

[23] M. F. Kadir, M. S. Bin Sayeed, and M. M. Mia, "Ethnopharmacological survey of medicinal plants used by traditional healers in Bangladesh for gastrointestinal disorders," Journal of Ethnopharmacology, vol. 147, no. 1, pp. 148-156, 2013. 

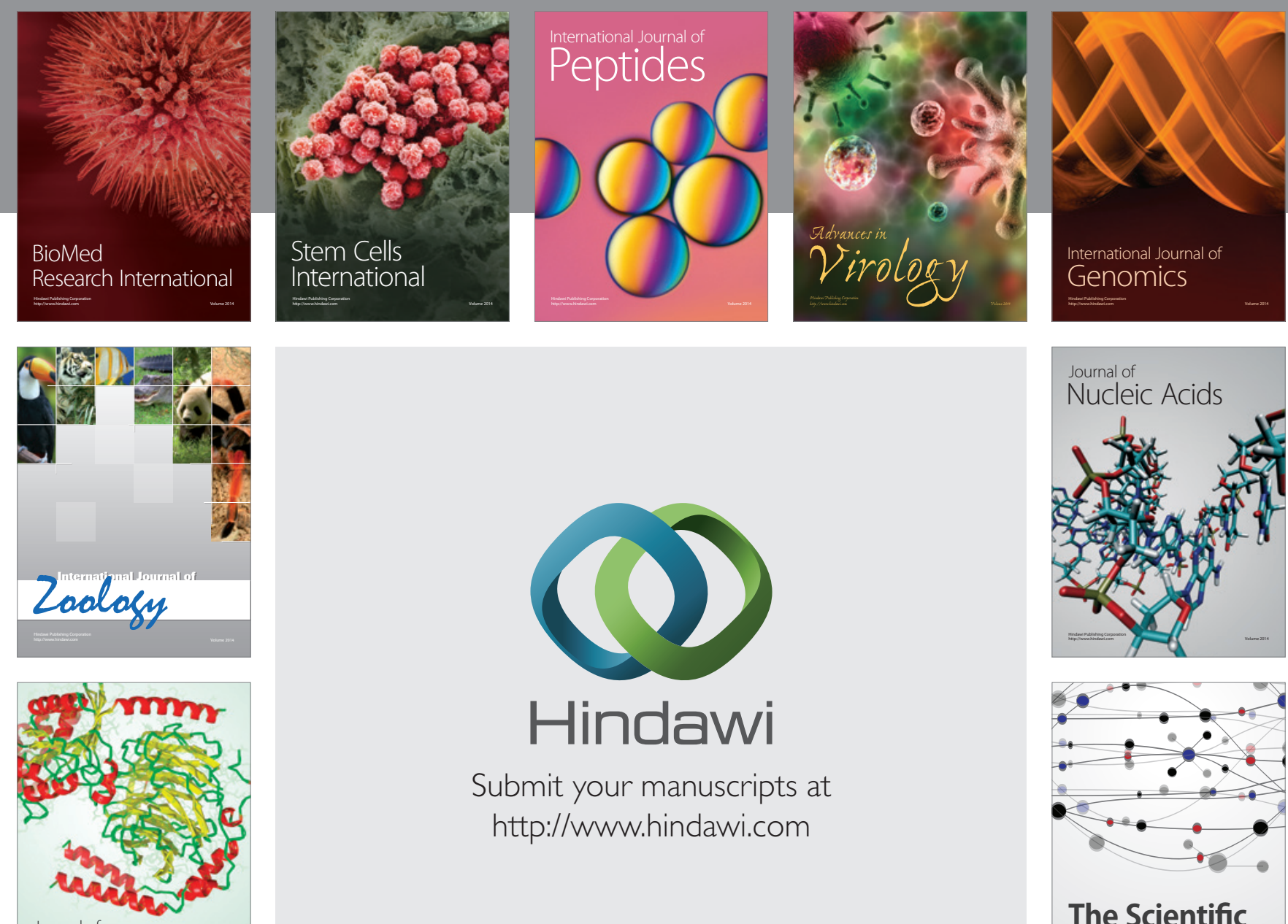

Submit your manuscripts at

http://www.hindawi.com

Journal of
Signal Transduction
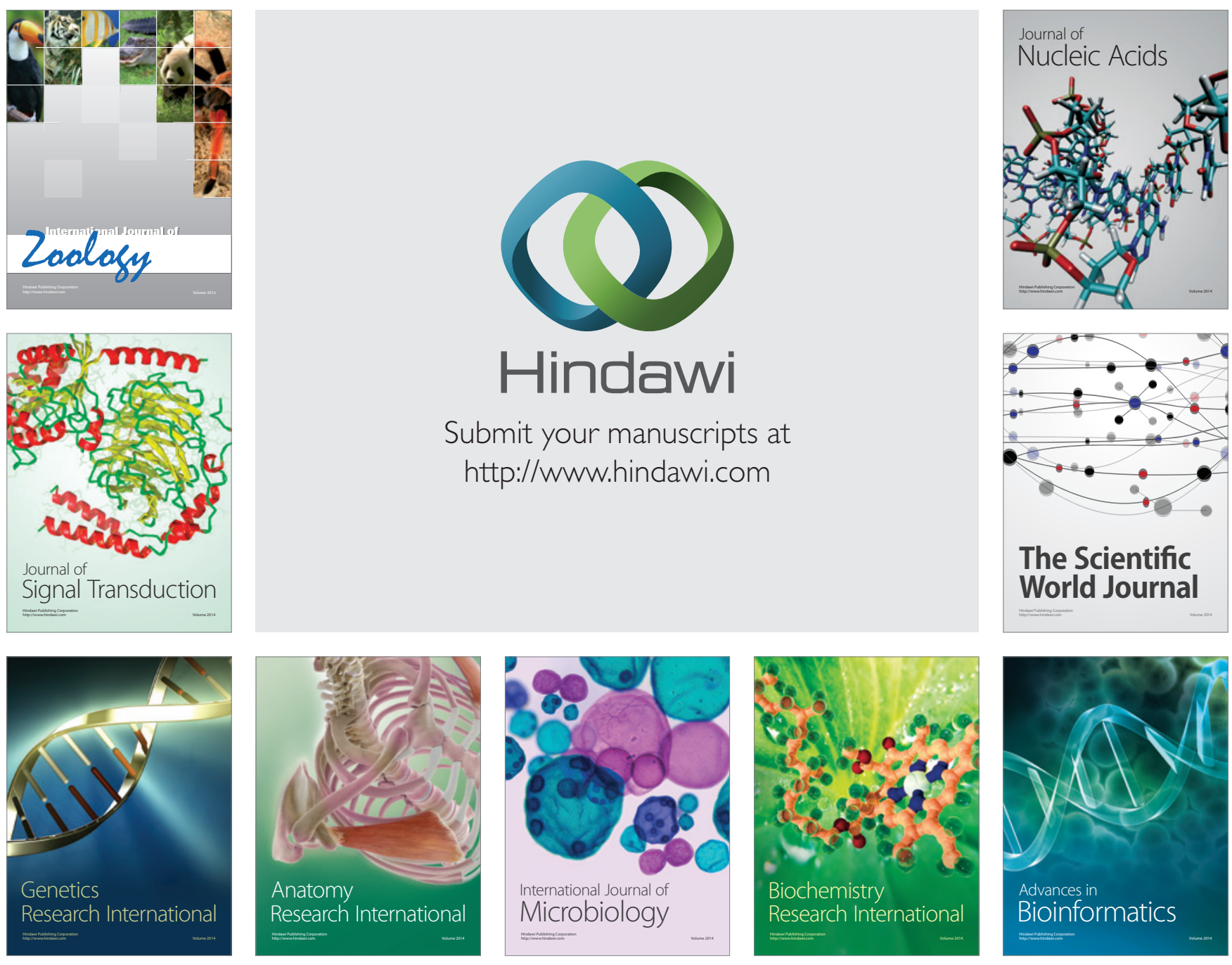

The Scientific World Journal
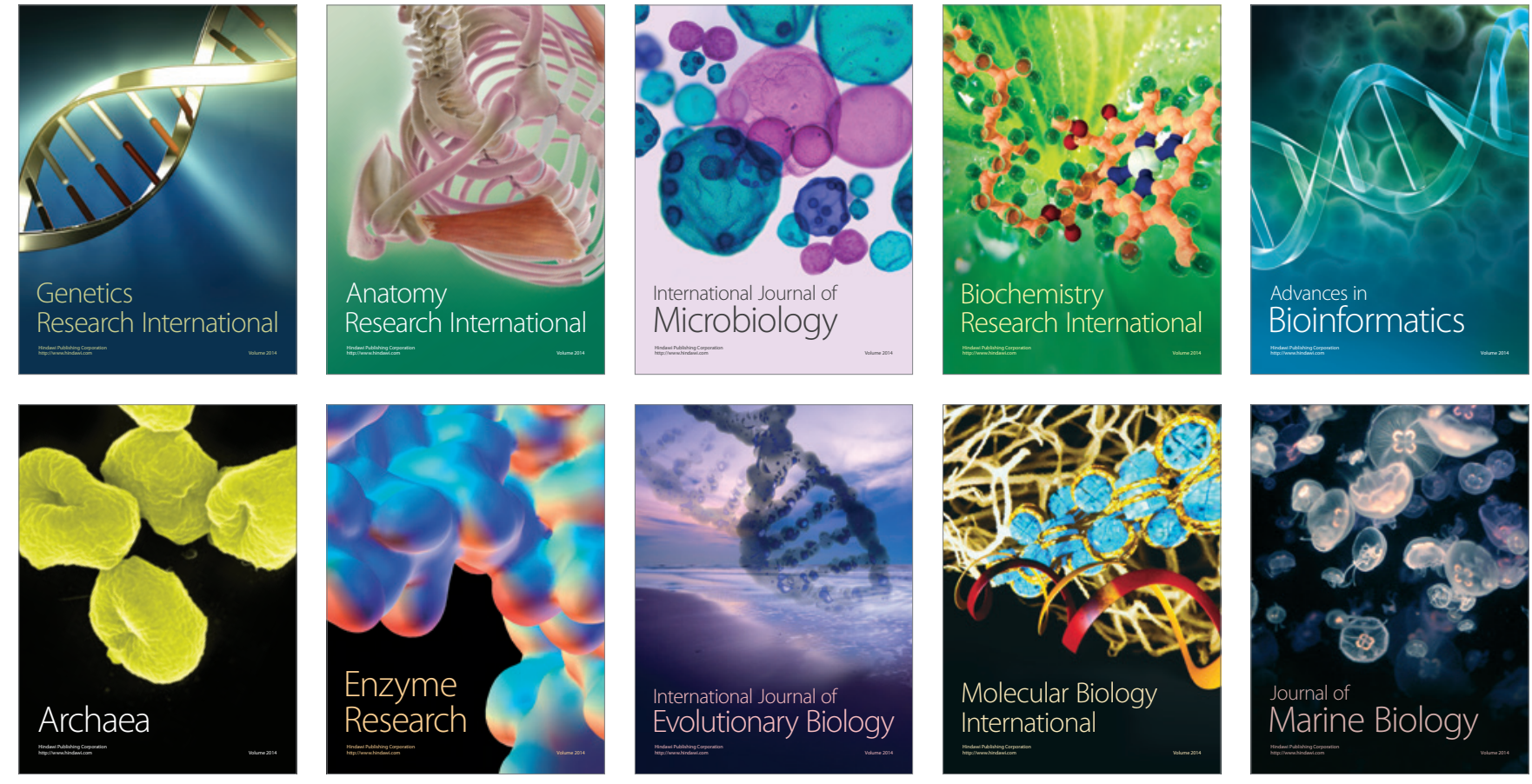